\title{
SUPRA-RENALITE EM CHAGÁSICOS CRÔNICOS
}

\section{Vicente de Paula Antunes Teixeira, Helenice Gobbi e Hipolito de Oliveira Almeida}

\begin{abstract}
O estudo das supra-renais de pacientes não chagásicos mostrou infiltrados linfocitários sempre discretos na cortical (30\%) e na medular (50\%). Nos chagásicos foram vistos infiltrados mononucleares no tecido perissupra-renálico em $83 \%$, na cortical em $53 \%$ e na medular em $93 \%$. Enquanto na cortical o exsudato foi sempre discreto ou moderado, na medular foi moderado em $30 \%$ e acentuado em $20 \%$. Em $27 \%$ dos chagásicos na medular das supra-renais havia também fibrose fina. Estes dados mostram que nos chagásicos crônicos a medular das supra-renais é acometida preferencialmente à cortical. É possível que o "parentesco" embriológico e funcional com o sistema nervoso autônomo esteja concorrendo para a existência de "caminhos patogenéticos" semelhantes para a ganglionite e medulite supra-renálica da iripanossomose crônica.
\end{abstract}

Palavras chaves: Doença de Chagas. Supra-renalite.

Em trabalho anterior ${ }^{2}$ encontramos reação inflamatória e parasitismo de células musculares da parede da veia central de supra-renais de chagásicos crônicos. Neste material, com certa freqüência, observamos infiltrado mononuclear no parênquima glandular. Revendo a literatura, constatamos que Chagas 5 e Vianna ${ }^{13}$ fazem referências a comprometimento das supra-renais em portadores da forma humana da doença de Chagas. Além disso Chagas ${ }^{5}$ relata o achado de formas em "leishmania" do Trypanosoma cruzi, no citoplasma de células corticais. Tratando-se, pois, de aspecto ainda pouco explorado desta protozoose, decidimos investigar de modo sistematizado alterações inflamatórias nas supra-renais de chagásicos crônicos comparando-as com observações em casos-controle.

\section{MATERIAL E MÉTODOS}

Foram utilizadas supra-renais de $\mathbf{4 0}$ individuos de ambos os sexos, necropsiados na Faculdade de Medicina do Triângulo Mineiro, sendo 30 chagásicos crônicos e 10 não-chagásicos (grupo de controle). Todos os chagásicos crônicos apresentavam reações de imunofluorescência e de fixação do complemento positivas para $T$. cruzi, sendo desprezados os casos de associação com outras doenças, particularmente tumores e inflamações crônicas. $\mathrm{O}$ grupo controle foi formado por individuos com reações sorológicas negativas para $T$. cruzi, vítimas de "morte violenta".

Disciplina de Patologia Geral da Faculdade de Medicina do Triângulo Mineiro - Uberaba, MG.

Recebido para publicação em 8/11/84
Após fixação em formol a 4\% (formol comercial a $10 \%$ ), as supra-renais eram cortadas transversalmente em 10 a 15 fatias e incluidas em parafina. De cada fatia, 10 lâminas eram cortadas e coradas pelo método de hematoxilina-eosina $\mathrm{e}$, algumas pelo método de Giemsa. O infiltrado leucocitário foi analisado separadamente na medular, na cortical e na cápsula fibrosa (incluindo gordura), sendo classificado em discreto $(+)$, moderado $(++)$ e acentuado $(+++)$. Critério semelhante foi usado na avaliação da fibrose na medular.

\section{RESULTADOS}

No grupo de controle as supra-renais exibiam cápsula fibrosa normal, sem espessamentos ou exsudato leucocitário. Tanto na medular quanto na cortical pode-se observar infiltrado mononuclear focal, sempre discreto (Tabela 1 e Figs. 1 e 2). Nos

Tabela 1-Exsudato mononuclear distribuido de acordo com sua localização e intensidade nas supra-renais de 10 controles nãochagásicos.

${ }_{\text {Localizaçáo }}^{\text {Intensidade }}++++++$ Total

Cápsula fibrosa e gordura peri-suprarrenálica

\begin{tabular}{lllll}
\hline Cortical & $3(30 \%)$ & - & - & $3(30 \%)$ \\
\hline Medular & $5(50 \%)$ & - & - & $5(50 \%)$ \\
\hline
\end{tabular}


Teixeira VPA, Gobbi H, Almeida HO. Supra-renalite em chagásicos crônicos. Revista da Sociedade Brasileira de Medicina Tropical 18: 155-159, Jul-Set, 1985

chagásicos crônicos as supra-renais podem apresentar alterações interpretáveis como de natureza inflamatória na cápsula fibrosa, na cortical e principalmente na medular (Tabela 2 e Figs. 3 a 6), além de flebite que deixamos de relatar aqui por ter sido objeto de trabalho anterior ${ }^{2} \mathrm{Na}$ cápsula e gordura peri-suprarrenálica o infiltrado é mononuclear, rico em células do tipo pequeno linfócito, geralmente focal discreto $(+)$, podendo no entanto ser moderado $(++)$ ou mais raramente acentuado $(+++)$. $\mathrm{Na}$ cortical foi encontrado exsudato qualitativamente semelhante ao da cápsula, porém em intensidade e freqüência menores. Na medular, onde é mais freqüente, pode atingir maior intensidade podendo ser focal ou difuso, sendo também mononuclear, porém mais rico em elementos da linhagem plasmocitária que na cortical e cápsula fibrosa. Em algumas áreas observa-se continuidade entre a flebite e o exsudato, na medular, porém, freqüentemente são independentes. As células do exsudato na medular aparentemente se associam tanto a feocromócitos como a neurônios ai existentes, os quais podem mostrar alterações de-

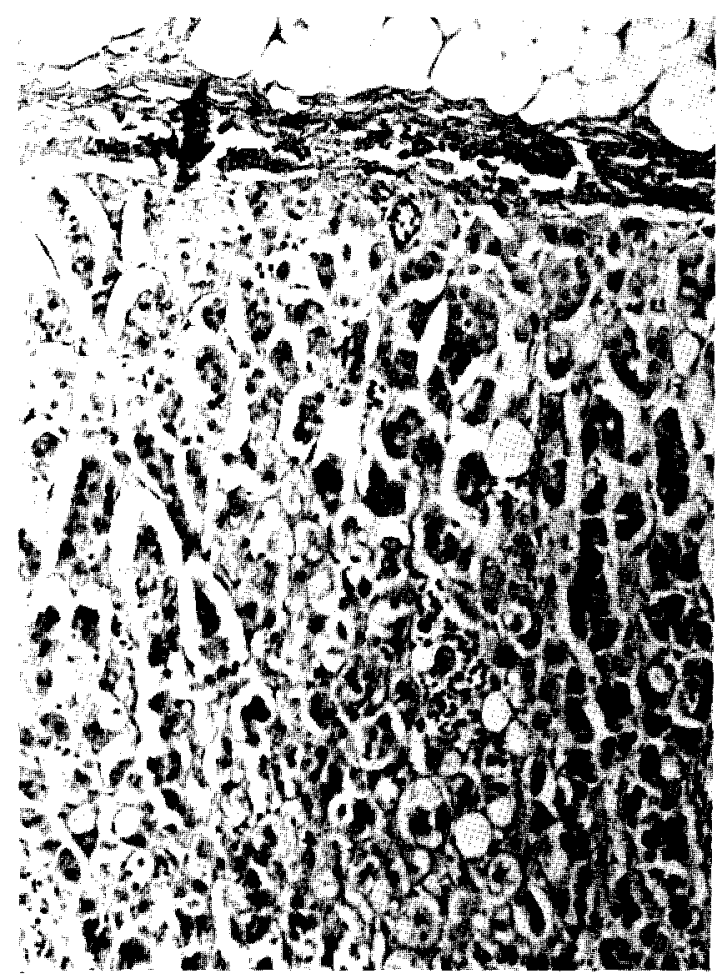

Figura 1-Supra-renal de caso controle mostrando pequeno foco de infiltrado linfocitário na cortical. A cápsula fibrosa e gordura peri-suprarrenálica são normais. $H E \times 63$.

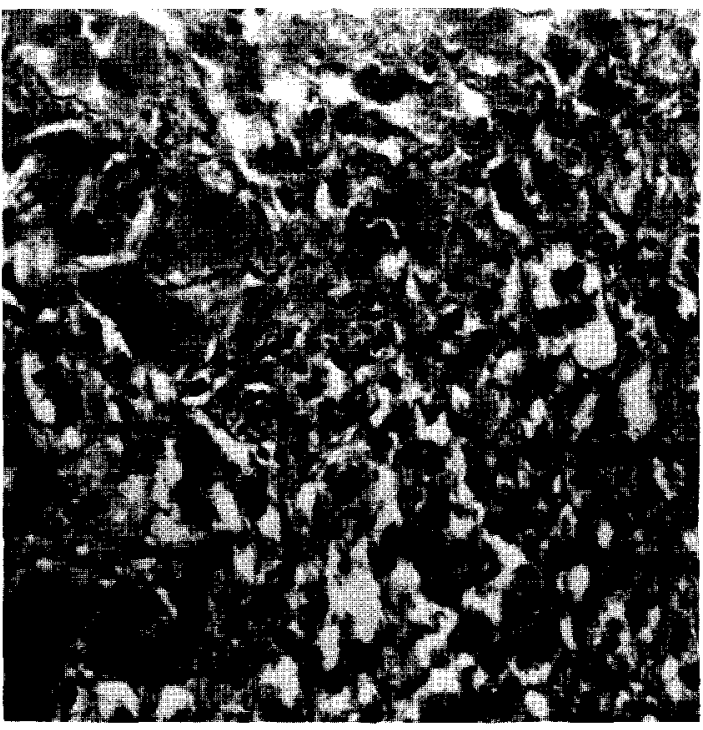

Figura 2 - Supra-renal de casos controle. Discreto infiltrado mononuclear na medular. $H E \times 63$.

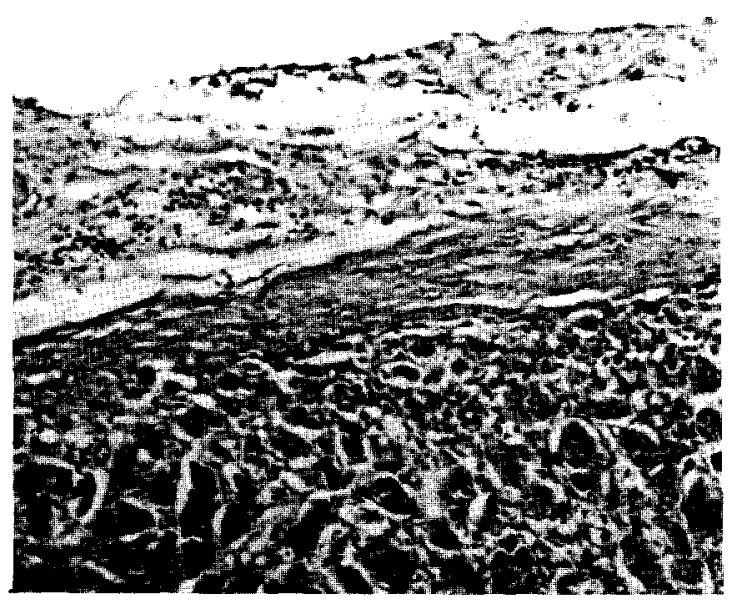

Figura 3 - Supra-renal de chagásico crônico. Observar a peri-suprarrenalite caracterizada principalmente por exsudato mononuclear. HE $\times 160$.

generativas, reduziram-se ou mesmo desapareceram na intimidade dos focos exsudativos. Além da exsudação, pudemos observar apenas na medular aumento de células fusiformes e depósito intersticial de material acidófilo, aparentemente fibrilar delicado em oito casos $(27 \%)$ ou mais raramente de material também acidófilo, amorfo, mais abundante. Não foram observados parasitos no tecido glandular cortical ou medular. 


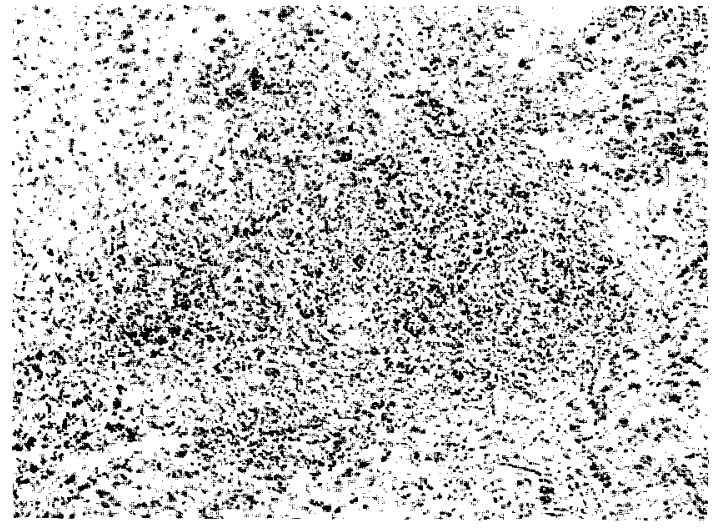

Figura 4-Supra-renal de chagásico crônico. O infiltrado de mononucleares na medular é acentuado, sendo discreto na cortical. $H E \times 63$.

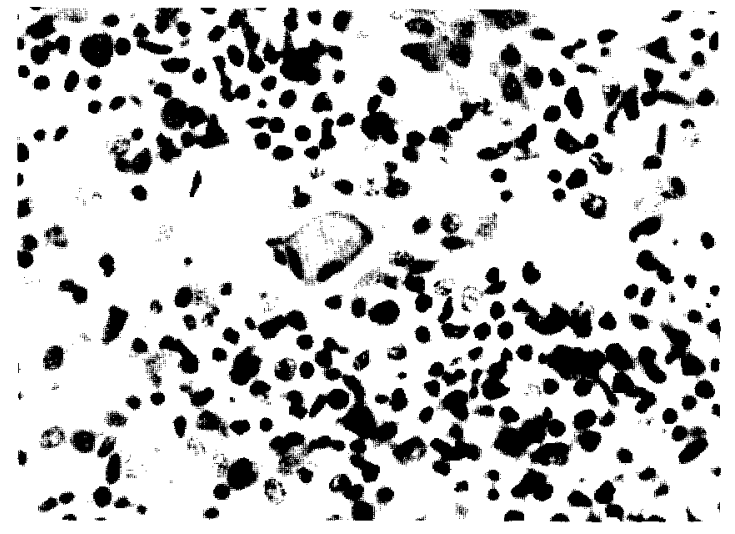

Figura 5 - Detalhe da Fig. 4, mostrando que o exsudato é constituído principalmente por células tipo pequeno linfócito associadas a plasmócitos e macrófagos. No centro observa-se um neurónio. $H E \times 160$.

Tabela 2 - Exsudato mononuclear distribuido de acordo com sua localização e intensidade nas supra-renais de 30 chagásicos crônicos.

\begin{tabular}{lcccc}
\hline \multicolumn{1}{c}{ Lntensidade } & + & ++ & +++ & Total \\
$\begin{array}{l}\text { Localizaçăo } \\
\begin{array}{l}\text { Cápsula fibrosa e gordura } \\
\text { peri-suprarrenálica }\end{array}\end{array}$ & $16(53 \%)$ & $6(20 \%)$ & $3(10 \%)$ & $25(83 \%)$ \\
\hline Cortical & $11(37 \%)$ & $5(17 \%)$ & - & $16(53 \%)$ \\
\hline Medular & $13(43 \%)$ & $9(30 \%)$ & $6(20 \%)$ & $28(93 \%)$ \\
\hline
\end{tabular}

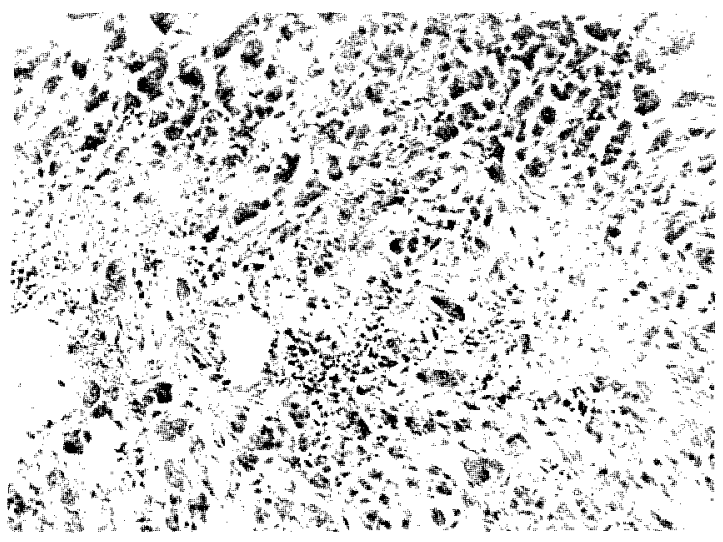

Figura 6-Supra-renal de chagásico crônico, mostrando na medular infiltrado mononuclear focal e proliferação difusa de elementos do estroma ( $f_{i}$ brose?). $H E \times 63$.

\section{DISCUSSÃO}

Em vários tratados de anatomia patológica os processos inflamatórios das supra-renais são mencionados apenas de passagem. A raridade das suprarenalites não granulomatosas tem sido relacionada à ação antiflogistica de hormônios corticais 10 . Sommers 10 denomina de "adrenalite focal" os acúmulos de linfócitos e plasmócitos localizados principalmente em torno de ramos venosos. Este autor considera tais infiltrados como secundários à inflamações crônicas retroperitoneais, como as pielonefrites. Entretanto, no presente estudo, observamos tais focos em supra-renais de individuos-controle, sem qualquer patologia inflamatória peritoneal, retroperitoneal ou mesmo em outros órgãos. Esta "adrenalite focal" dos não-chagásicos foi sempre discreta e restrita a pequenos acúmulos leucocitários no córtex ou na medular. $O$ quadro das supra-renais dos 
Teixeira VPA, Gobbi H, Almeida HO. Supra-renalite em chagásicos crônicos. Revista da Sociedade Brasileira de Medicina Tropical 18: 155-159, Jul-Set, 1985

chagásicos crônicos mostra aspectos que nos parecem suficientes para caracterizar a existência de uma "supra-renalite chagásica", constituida pelo comprometimento do tecido glandular (medular principalmente) e pela flebite associada a ninhos de amastigotas, já descrita anteriormente ${ }^{2}$. A perissuprarenalite pela sua freqüencia alta $(83 \%)$ e pelo fato de não ter sido encontrada nos controles, constitui um elemento importante para auxiliar no diagnóstico de comprometimento da supra-renal pela tripanossomose americana, guardando uma certa semelhança com a epicardite do coração chagásico crônico. É provável que ambas tenham mecanismos patogenéticos comuns, uma vez que a gordura uni- e multilocular e o conjuntivo fibroso são lesados tanto no epicárdio como em torno das supra-renais. Raso e Tafuri ${ }^{8}$ admitem um certo "tropismo" do T. cruzi para o tecido adiposo como um dos prováveis fenômenos responsáveis pela freqüência da epicardite. Fato semelhante poderia concorrer para a perissupra-renalite, apesar de nào existirem dados que comprovem a existência de tropismo do $T$. cruzi para o tecido adiposo humano.

$O$ processo inflamatório que se observa nas supra-renais dos chagásicos crônicos mostra nítida predileção pela zona medular, sendo a cortical menos atingida. De fato, $43 \%$ dos chagásicos examinados exibiam exsudato mononuclear discreto, $30 \%$ moderado e $20 \%$ acentuado, perfazendo um total de 93\% de ocorrência de infiltrado mononuclear na medula das supra-renais dos chagásicos crônicos. Em $27 \%$ destes pacientes havia também proliferação de células fusiformes do tipo fibroblasto e depósito de material fibrilar delicado, que parecem representar um fenômeno produtivo da inflamação que aí é pouco intenso e não assume o aspecto cicatricial observado com freqüência no coração de chagásicos crôni$\cos ^{13} 467$. É possivel que condições hormonais locais e a ausência de mastócitos ${ }^{2}$, dentre outros fatores, possam contribuir para a característica apontada.

É interessante notar que sendo a medular das supra-renais derivada das cristas neurais, como o sistema nervoso autônomo, e tendo com este algumas semelhanças metabólicas, também sofra nos chagásicos crônicos agressão inflamatória freqüente e por vezes bastante acentuada. $\dot{\mathrm{E}}$, pois, de se admitir que tal parentesco embriológico e funcional esteja concorrendo para a existência de "caminhos patogenéticos" semelhantes para a ganglionite e medulite da supra-renal dos chagásicos crônicos. Teixeira 11 e Teixeira e cols 12 admitem que a antigenicidade cruzada entre o $T$. cruzi e células do sistema nervoso autônomo seria importante fator determinante da agressão neuronal por células do sistema imunitário do chagásico, sensibilizadas contra este antigeno comum a neurônios e tripanossomas. Poderiamos, pois, admitir que dentre os antigenos comuns a feocromócitos e neurônios estariam aqueles (ou aquele) responsáveis pela antigenicidade cruzada com o $T$. cruzi. Entretanto, Ribeiro dos Santos e Hudson ${ }^{9}$ descrevem adsorção de antigenos parasitários na superficie de células nervosas e admitem-na como responsável pelas lesões ganglionares no chagásico. Fato semelhante poderia estar participando da gênese da medulite que ora relatamos.

Apesar de bem caracterizadas estas alteraçōes inflamatórias nas supra-renais dos chagásicos crônicos, particularmente a medulite, são necessários outros estudos para avaliarmos uma possivel expressão fisiopatológica destas alterações morfológicas que começam a ser analisadas.

\section{AGRADECIMENTOS}

Auxiliaram na realização deste trabalho: Dóris T. B. Chamahum, José Henrique Cruvinel da Silva e Maria Prado de Morais (histotecnologia); Raimundo N. C. Laranja (fotografia); Ana Palmira Soares dos Santos (datilografia).

\section{SUMMARY}

The study of adrenals of non chagasic control patients shows a mild lymphocytic infiltrate in the cortex in $30 \%$ of the cases and in the medulla in $50 \%$ of the cases. $83 \%$ of chronic chagasic patients reveal mononuclear infiltrate in periadrenal tissue, $53 \%$ in the cortex and $93 \%$ in the medulla. In the cortex the exudate was always mild or moderate and in the medulla it was moderate in $30 \%$ and intense in $20 \%$ of the cases. The medulla of chagasic patients also shows slight fibrosis, in $27 \%$ of cases. The data show that the medulla of the adrenals of chagasics is involved preferentially if compared with the cortex. It is possible that the embryologic and functional relationship with the autonomous nervous system, may contribute to similar pathogenetic mechanisms in the ganglionitis and "adrenal medullitis" of the chronic trypanosomiasis.

Key words: Chagas' disease. Adrenal involvement. 
Teixeira VPA, Gobbi H, Almeida HO. Supra-renalite em chagásicos crônicos. Revista da Sociedade Brasileira de Medicina Tropical 18: 155-159. Jul-Set, 1985

\section{REFERÊNCIAS BIBLIOGRÁFICAS}

1. Almeida HO. A lesão vorticilar na cardiopatia chagásica crônica. Tese de Doutoramento. Faculdade de Medicina da Universidade Federal de Minas Gerais, Belo Horizonte, 1978.

2. Almeida HO, Teixeira VPA, Oliveira ACF. Flebite com parasitismo em supra-renais de chagásicos crônicos. Arquivos Brasileiros de Cardiologia 36:341-344, 1981,

3. Almeida HO. A cardiopatia em chagásicos crônicos com e sem "megas". Tese de Professor Titular, Faculdade de Medicina do Triângulo Mineiro, Uberaba, Minas Gerais, 1982.

4. Andrade ZA, Andrade SG. Patologia. In: Brener $Z$ e Andrade $Z$ (ed.) Trypanosoma cruzi e doença de Chagas. Ed. Guanabara-Koogan, Rio de Janeiro, p. 199, 1979.

5. Chagas C. Processos patogênicos da tripanosomiase americana. Memórias do Instituto Oswaldo Cruz, VIII, 1916. Reimpresso em Carlos Chagas - Coletânea de trabalhos cientificos. Coleção temas Brasileiros 6:385$417,1981$.

6. Mazza S, Jorge ME, Feijó ORJC. Primeiro caso crônico mortal da forma cardiaca da enfermidade de Chagas demonstrado em Santiago del Estero. Publication M.E.P.R.A. no 39, 1938.
7. Mignone C. Alguns aspectos da anatomia patológica da cardite chagásica crônica. Tese de Professor Catedrático. Faculdade de Medicina da Universidade de São Paulo, São Paulo, 1958.

8. Raso P, Tafuri WL. Alterações do pericárdio na fase crônica da tripanosomose cruzi e nas fases agudas e crônica da moléstia experimental. Revista da Sociedade Brasileira de Medicina Tropical 5:135-153, 1971.

9. Ribeiro dos Santos R, Hudson L. Trypanosoma cruzi: Adsorption of parasite antigens to mammalian cell surfaces. Parasite Immunology 2:1-10, 1980.

10. Sommers SC. Adrenal gland In: Anderson WAD (ed) Pathology 7th ed. C.V. Mosby Co, St. Louis, p. 1658$1679,1977$.

11. Teixeira ARL. Competência imunológica do paciente chagásico. Tese, Faculdade de Ciências da Saúde, Universidade Brasília, Brasilia 1979.

12. Teixeira ARL, Teixeira ML, Santos Buch CA. The immunology of experimental Chagas' disease. IV. The production of lesions in rabbits similar to those of chronic Chagas' disease in man. American Journal of Pathololgy 80:163-180, 1975.

13. Vianna G. Contribuição para o estudo da anatomia patológica da "moléstia de Carlos Chagas". Memórias do Instituto Oswaldo Cruz 8: 276-294, 1911. 